\title{
Lateral Pile Response Subjected to Different Combination of Loadings
}

\author{
Jasim M. Abbas ${ }^{1}$, Zamri Chik ${ }^{2}$ and Mohd Raihan Taha ${ }^{2}$ \\ Department of Civil Engineering, Diyala University, Iraq \\ Department of Civil and Structural Engineering, Universiti Kebangsaan Malaysia
}

Received 21 November 2016; Accepted 20 December 2017

\begin{abstract}
Pile-soil interaction has been a subject of interest to many earlier researchers. However, not much work has been done on the effects of structural response of single piles subjected to different combination of axial and lateral loads and hence the respective pile-soil interaction. The main objectives of this paper are to assess the influence of axial load intensities on the lateral single isolated pile response in various pile slenderness ratios. Three-dimensional finite element approach was used to simulate the whole geotechnical system. The finite element included linear elastic model to represent the pile, Mohr-Coulomb to model surrounded soil and 16-nodes interface element to simulate the pile-soil interface. It was found that the lateral deflection is increased with increased the axial load in case of cohesionless soils. While, in case of cohesive soil, reduction in lateral pile displacement is occurred when low axial load is applied (i.e. V less than $4 \mathrm{H}$ ) and increased when axial load level (i.e. V more than $6 \mathrm{H}$ ) has been increased.
\end{abstract}

Keywords: piles, lateral response, combined load, 3D FE analysis, cohesionless and cohesive soils

\section{Introduction}

In most practical situations, there is a need to assess the behavior of piles under simultaneous vertical and horizontal loadings because piles are commonly designed to carry either horizontal or vertical loads [1,2]. Nevertheless, in long buildings such as bridges abutments, offshore structure, transmission towers, etc., the piles carry not only axial load but also combination of axial (vertical) and lateral (horizontal) forces. The amount of lateral load is about 10 $20 \%$ from applied axial load [3]. In the design of pile subjected to lateral load, the ultimate lateral resistance of pile is required to satisfy two criteria [3, 4], (i) pile should be safe against failure; and (ii) normal deflection at working loads should be within the permissible limit.

In the case of lateral loaded pile, the developed p-y curve is always depending on the lateral load intensity. The developed p-y curve is probably influenced by the level of the axial load. This is because of the fact that pile foundations are frequently used to support lateral loading as well as axial loading in the same time. Therefore, the axial load makes a change on the lateral pile response [1 ,2]. Even so, this issue was not observed enough in previous studies. However, it needs more assessment specially using numerical technique due to both analytical and experimental studies rather limited to overcome this complex problem. Thus, the main objective of this study is to assess the influence of soil type and pile slenderness ratio on the lateral pile response under different combination of loads.

The axial load is mainly resulted from the superstructure dead and live loads. While, the main source of lateral load is resulted from the super structure itself, for example, pile support offshore structure, transmission tower, bridge piers

\footnotetext{
*E-mail address: mashahid79@gmail.com

ISSN: 1791-2377 @ 2017 Eastern Macedonia and Thrace Institute of Technology. All rights reserved. doi:10.25103/jestr.106.25
}

and other types of huge building abutments. In these types, the structures resting on piles are frequently exposed to wind, traffic and seismic loads that generate horizontal forces in the piles. In addition, the source of lateral load occurred at the same time when the pile has already designed to support pure lateral loadings. The lateral load maybe also resulted from the nature, for example lateral soil movement.

During the recent time, the pile was analyzed using several methods. These methods were developed to improve the assessment of the pile in pure lateral load, for example $[1,5,6,7,8,9$ and 10]. Whereas, few researches observed include the analysis of the pile under different combination of axial and lateral load as reported by Karthigeyan et al., [1, 2]. This assessment was limited and not covered for example the influence of slenderness ratio on the lateral pile response. In addition this study did not address the influence of load combination on the predicted p-y curve.

Therefore, the intention of this study is to evaluate the lateral pile response in two types of soil as well as various pile slenderness ratio by using three-dimensional finite element approach. Taking into account the influence of axial load level on the lateral pile displacement, lateral soil pressure and corresponding $\mathrm{p}-\mathrm{y}$ design curves.

\section{Analysis Methodology and Layout}

Finite element analyses were performed using the software PLAXIS 3D Foundation. In the finite element method a continuum is divided into a number of (volume) elements. Each element consists of a number of nodes. Each node has a number of degrees of freedom that correspond to discrete values of the unknowns in the boundary value problem to be solved. The finite element mesh used in the simulation of single pile analysis (shown in Figure 1) consists of (1134) 15-nodes wedge element, including (1099) soil element and (35) pile element. The lateral load is applied at the tip of the 
pile that is found at the ground surface in the $\mathrm{x}$-direction and at $y$-direction when axial loads are applied. Plan and 3D view for the finite element mesh of single pile and surrounded soil mass is illustrated in Figure 1. The outer boundaries of soil body of cubic shape are extended to $10 \mathrm{D}$ on the sides and 5D at the bottom of pile base.

Analyses were performed with several trial meshes with increasing mesh refinement until the displacement changes to very minimal with more refinement. The aspect ratio of elements used in the mesh is small and close to the pile body near to the pile top and base. All the nodes of the lateral boundaries (right and bottom) are restrained from moving in the normal direction to the respective surface.
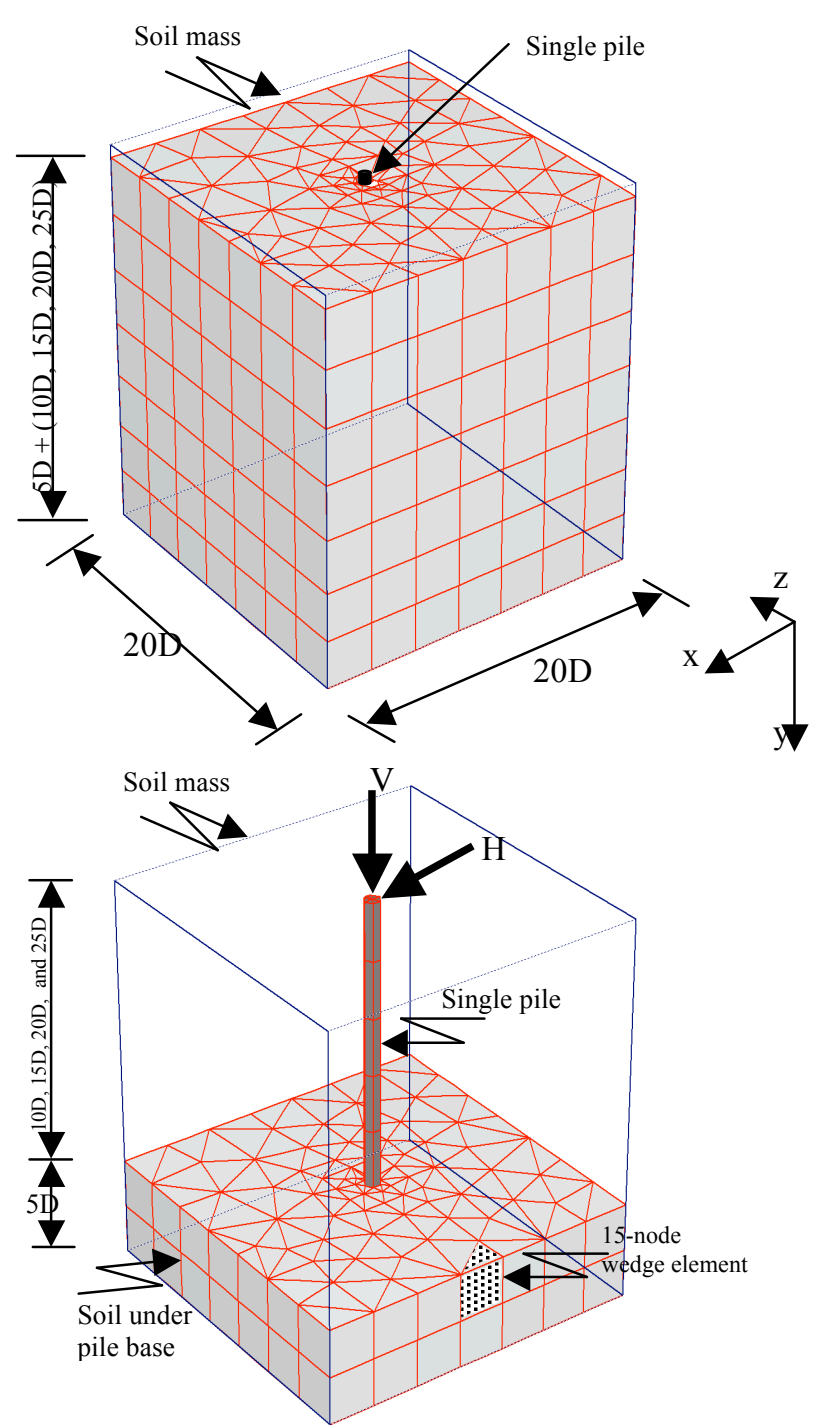

Fig. 1 Three-dimension finite element mesh of single pile and surrounded soil mass

The finite element simulation includes the following constitutive relationships for pile, surrounded soil and interface element. The finite element includes linear elastic model to simulate structural part of problem (e.g. pile), Mohr-Coulomb model to represent the surrounded soil and 16-node interface elements to represent interface element. These constitutive models are illustrated as follow:
Structural Members Model: The use of the linear elastic model is quite common to model massive structures in the soil or bedrock layers which include piles [11]. This model represents Hooke's law of isotropic linear elasticity used for modeling the stress-strain relationship of the pile material. The model involves two elastic stiffness parameters, namely the effective Young's modulus, $E^{\prime}$, and the effective Poisson's ratio, $v^{\prime}$.

Soil Model: The surrounding soil is represented by MohrCoulomb's model. This elasto-plastic model is based on soil parameters that are known in most practical situations. The model involves two main parameters, namely the cohesion intercept, $c^{\prime}$ and the friction angle, $\varphi^{\prime}$. In addition, three parameters namely Young's modulus, $E$ ', Poisson's ratio, v', and the dilatancy angle, $\psi$ ' are needed to calculate the complete stress-strain behavior. The failure envelope as referred by $[12,13]$ only depends on the principal stresses $\left(\sigma_{1}, \sigma_{3}\right)$, and is independent of the intermediate principle stress $\left(\sigma_{2}^{\prime}\right)$.

Interface Elements Model: Interfaces are modeled as 16node interface elements. Interface elements consist of eight pairs of nodes, compatible with the 8-noded quadrilateral side of a soil element. Along degenerated soil elements, interface elements are composed of six node pairs, compatible with the triangular side of the degenerated soil element. Each interface has a virtual thickness assigned to it which is an imaginary dimension used to obtain the stiffness properties of the interface. The virtual thickness is defined as the virtual thickness factor times the average element size.

\section{Validation of the Numerical Model}

The finite element approach is used in this study to predict the performance of pile when carrying pure lateral load and combination of axial and lateral loads. This section assesses the accuracy of the finite element approach in analyzing laterally loaded piles and to verify certain details of the finite element such as pile displacement. According to literature, there are no published cases of full-scale lateral pile response subjected to different combination of axial and lateral loads. Therefore, to cover the aim of this research, two case studies were used. The first deals with a full-scale axial loaded pile [14] to make a comparison with case study of axial loaded piles. In addition, the second includes fullscale lateral load tests reported by [15] to assess the lateral pile response under lateral load. Results of laboratory and field tests are used to identify the soil profiles and soil properties. Both pile load tests are well instrumented. The details of studied cases of pile load tests and simulation of the load tests using 3D finite element approach will be followed in the next sections to make a comparison between the real field tests and numerical finite element simulation.

\subsection{Case 1 [14]}

The first case study consists of a large diameter bored piles of $1.2 \mathrm{~m}$ diameter which were used for the construction of a new $2.2 \mathrm{~km}$ road dual carriageway viaduct on an existing road [14]. The road project is situated in Port Klang, and links the West Port to Kuala Lumpur, Malaysia. The piles were tested vertically to assess the axial bearing capacity of designed piles. The length of each bored pile is approximately $75 \mathrm{~m}$ with steel casing being used for the top $30 \mathrm{~m}$. The bored piles were designed to carry loads ranging 
from 300 to $600 \mathrm{kN}$. The generalized subsoil properties consist of very soft silty clay with traces of sea shells with depth $20 \mathrm{~m}$. Below this layer is a $10 \mathrm{~m}$ of soft silty clay followed by a layer of medium dense to dense silty sand and medium stiff silty clay of about $20 \mathrm{~m}$ and $7 \mathrm{~m}$ depth, respectively. Finally the lowest layer consists of very dense fine grained sand. The soil and pile properties are illustrated in Table 1.

The comparison between the finite element results and field test data are shown in Figure 2. Comparable data were Table 1. Geotechnical properties of the soil layers [14] obtained between the experimental results of the three piles and the presented simulation model in the case of axial test. The magnitude of deflection of the piles was not the same as the field test due possibly to the variability of soil properties. The result obtained from the finite element simulation is closer to the result measured from pile number one.

\begin{tabular}{|c|c|c|c|c|c|c|}
\hline & $\begin{array}{c}\text { Unsat- } \\
\text { urated } \\
\text { soil weight } \\
\left(\mathrm{kN} / \mathrm{m}^{3}\right)\end{array}$ & $\begin{array}{c}\text { Saturated } \\
\text { soil weight } \\
\left(\mathrm{kN} / \mathbf{m}^{3}\right)\end{array}$ & $\begin{array}{c}\text { Young's } \\
\text { Modulus } \\
(\mathrm{kPa}) \\
\end{array}$ & $\begin{array}{l}\text { Poisson's } \\
\text { ratio }\end{array}$ & $\begin{array}{c}\text { Cohesion } \\
\text { intercept } \\
(\mathrm{kPa}) \\
\end{array}$ & $\begin{array}{r}\text { Friction } \\
\text { angle }\end{array}$ \\
\hline $\begin{array}{l}\text { Very soft silty clay } \\
\text { with traces of sea } \\
\text { shells }\end{array}$ & 14 & 16 & 8500 & 0.3 & 10 & 21 \\
\hline Soft silty clay & 16 & 18 & 10000 & 0.35 & 5 & 25 \\
\hline $\begin{array}{l}\text { Medium dense to } \\
\text { dense silty sand }\end{array}$ & 19 & 19 & 13000 & 0.3 & 1 & 45 \\
\hline $\begin{array}{l}\text { Medium stiff silty } \\
\text { clay }\end{array}$ & 16 & 18 & 10000 & 0.35 & 5 & 25 \\
\hline $\begin{array}{l}\text { Very dense fine } \\
\text { grained sand }\end{array}$ & 17 & 20 & 14000 & 0.3 & 1 & 31 \\
\hline $\begin{array}{l}\text { Pile } \\
\text { Pil }\end{array}$ & 25 & - & $2 \times 10^{9}$ & 0.15 & - & - \\
\hline
\end{tabular}

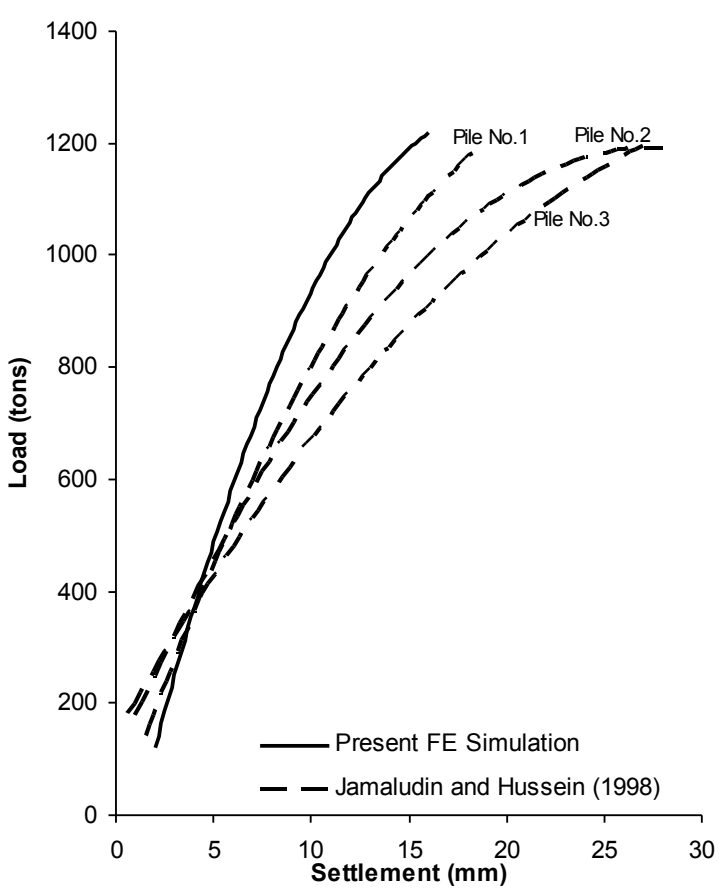

Fig. 2. Comparison of finite element results with field test data of [14]
The second case study deals with lateral load in which the deflection response of bored piles in cemented sand were examined by field test on a single pile under lateral load [15]. All piles were $0.3 \mathrm{~m}$ in diameter and had a length of $3 \mathrm{~m}$ or $5 \mathrm{~m}$. The site of this load test was in Kuwait. The soil profile consists of a medium dense cemented silty sand layer to a depth of $3 \mathrm{~m}$. This is underlined by a medium dense to very dense silty sand with cemented lumps to the bottom of the borehole. The same load sequence as pile tests was applied on the pile after completing the whole geotechnical model for lateral pile tests. The properties of soil in both cases are listed in Table 2.

The comparison between the finite element results and field test data are shown in Figure 3. The numerical simulation is reasonably accurate for the problem of laterally loaded piles and pile-soil interaction over a wide range of deformation for $3 \mathrm{~m}$ and $5 \mathrm{~m}$ piles long. The pile with length $5 \mathrm{~m}$ is highly resistance to the lateral load from the second pile length value. Comparable data were obtained between the experimental results of the three piles and the present simulation model. The results obtained from the numerical simulation for pile of $5 \mathrm{~m}$ is relatively closed with the results obtained from the field test. The result from the numerical simulation is not too closed in case of $3 \mathrm{~m}$ length pile. This maybe due to non-homogenous soil around the pile in field.

\subsection{Case 2 [15]}

Table 2 Geotechnical properties of the soil layers

\begin{tabular}{|c|c|c|c|c|c|}
\hline 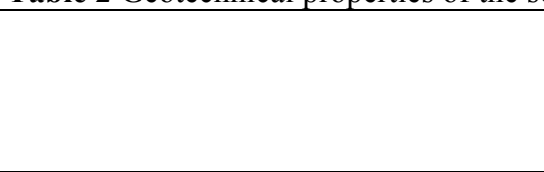 & $\begin{array}{l}\text { Saturated } \\
\text { soil weight } \\
\left(\mathrm{kN} / \mathrm{m}^{3}\right)\end{array}$ & $\begin{array}{l}\text { Young's } \\
\text { Modulus } \\
(\mathrm{kPa})\end{array}$ & $\begin{array}{l}\text { Poisson's } \\
\text { ratio }\end{array}$ & $\begin{array}{l}\text { Cohesion } \\
\text { intercept } \\
(\mathrm{kPa})\end{array}$ & $\begin{array}{l}\text { Friction } \\
\text { angle }\end{array}$ \\
\hline $\begin{array}{l}\text { Medium dense cemented silty sand } \\
\text { layer }\end{array}$ & 18 & $1.3 \times 104$ & 0.3 & 20 & 35 \\
\hline $\begin{array}{l}\text { Medium dense to very dense silty } \\
\text { sand with cemented lumps } \\
\text { Pile }\end{array}$ & $\begin{array}{l}19 \\
-\end{array}$ & $\begin{array}{l}1.3 \times 104 \\
2.0 \times 109\end{array}$ & $\begin{array}{l}0.3 \\
0.15\end{array}$ & $\begin{array}{l}1 \\
-\end{array}$ & $\begin{array}{l}45 \\
-\end{array}$ \\
\hline
\end{tabular}




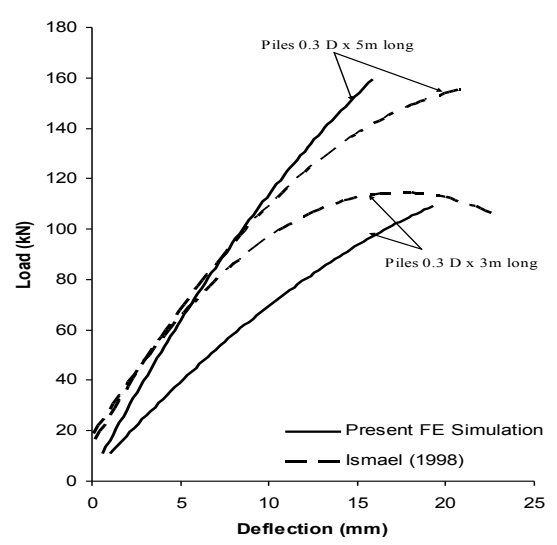

Fig. 3. Comparison of finite element results with field test data of [15]
This section deals with the effect of vertical load intensity on the lateral behavior of pile. The vertical load applied started from zero (no vertical load) to 10 times the lateral load and was increased in five stages (i.e. $\mathrm{V}=2 \mathrm{H}, 4 \mathrm{H}, 6 \mathrm{H}, 8 \mathrm{H}$ and $10 \mathrm{H})$. Lateral load during this stage was varied at 50, 250 and $450 \mathrm{kN}$. This study includes: (a) influence of the axial load intensity on lateral pile response, (b) effect of soil type, two types of soil represented by cohesionless and cohesive soil, and (c) effect of the slenderness ratio (L/D), which various between $\mathrm{L} / \mathrm{D}=10-25$. The influence of these mentioned factors are summarized in the following sections. The baseline soil parameters used for the analysis of laterally loaded pile group are illustrated in Table 3 .

\section{Results and Discussions}

Table 3. Soil parameters for analysis of pile group

\begin{tabular}{l|l|l|l}
\hline Parameter & Unit & Coh.less & Cohesive \\
\hline Unit weight, $\gamma^{\prime}$ & $\mathrm{kN} / \mathrm{m}^{3}$ & 20.0 & 18.0 \\
Young's modulus, $E^{\prime}$ & $\mathrm{MPa}$ & $1.3 \times 10^{4}$ & $1.0 \times 10^{4}$ \\
Poisson's ratio, $v^{\prime}$, & - & 0.3 & 0.35 \\
Cohesion intercept, $c^{\prime}$ & $\mathrm{MPa}$ & 0.1 & 5.0 \\
Angle of internal friction,,${ }^{\prime}$ & - & 30 & 25 \\
\hline
\end{tabular}

\subsection{Evaluation of lateral pile displacement}

Distribution of lateral displacement along the pile depth for a pile carried pure lateral load as well as five axial load intensities in both cohesionless and cohesive soil are shown in Figure 4. Changes are evident on the lateral pile displacement when comparing between the pile with pure lateral load and when the pile carried both axial and lateral load. In addition, a change also occurred after the increase in the applied axial load from the lowest value (i.e. 10H) to the highest magnitude (i.e. $10 \mathrm{H}$ ).

Karthigeyan et al., [1 ,2] observed that for piles in cohesionless soil, the vertical loads decrease the lateral deflection thus increasing the lateral load capacity of the piles. On the other hand, in cohesive soils, the axial loads decrease the lateral pile capacity. In this study, in case of cohesionless soil, it was found that the deflection reduces (increased capacity) especially at $2 \mathrm{H}$ and $4 \mathrm{H}$ vertical loadings, subsequently the deflection increases slightly (reduction in capacity) when applied axial loads more than $6 \mathrm{H}$. On the other hand, for the case of cohesive soils, the lateral deflection increases with axial load indicating reduction in the lateral capacity of the piles. This behavior was also observed by $[1,2]$

In general, the maximum lateral pile displacement occurred in the pile tip. It can be noticed that the pile with slenderness ratio of $10 \mathrm{D}$ (short pile) has a point of rotation located between 2-2.5D from the base of pile. For this type of pile, it can be measured a negative deflection that always found near to the pile base. While, the pile with slenderness ratio of $15 \mathrm{D}$ has point of rotation at $6 \mathrm{D}$ from the base, with very small amount of negative pile displacement. In case of pile slenderness ratios $20 \mathrm{D}$ and $25 \mathrm{D}$, the pile has fracture point at $12 \mathrm{D}$ and $15 \mathrm{D}$ from the pile base, respectively, with very small and same time zero negative lateral displacement. The maximum tip deflections vs. pile slenderness ratio are detailed in Figure 5. This design plot is generated for various slenderness ratio of pile subjected to simultaneous axial and lateral load. In general, the behavior under low axial load amount is significantly close to the linear response. While, at higher axial load intensity (more than $6 \mathrm{H}$ ), the piles behaved non-uniformly as a result from non-linear response of soil around pile and this is supported by [14]. It can be observed that the pile in cohesionless soil is less sensitive than pile in cohesive soil for the pile slenderness ratio less than $10 \mathrm{D}$. This is possibly due to large resistance of cohesionless soil compared with cohesive soil. This design curves shown in Figure 5 is predicted from several assessment of the different pile slenderness ratio. These curves can be used to estimate the maximum lateral pile displacements in different combination of load and various pile slenderness ration.

\subsection{Evaluation of lateral soil pressure}

Lateral soil pressures $(p)$ in cohesionless and cohesive soils that resulted from the combination of axial and lateral loads at two time factors are shown in Figure 6. It can be seen that the axial load intensity affects the lateral soil pressures. The values of maximum lateral soil pressure occurred at $\mathrm{L} / 5 \mathrm{D}$ from the ground surface (pile tip). This depth represents critical depth for analysis and design of a single isolated loaded pile as reported by $[1,2]$

One of the main findings is that the surface resistance for both cases of cohesionless and cohesive soil reached minimum value but did not reach zero under all vertical loads. This finding is similar to [16] who again obtained the results without vertical loads. In addition as can be seen in the case of cohesionless soil, the values of lateral soil pressure at the surface observed were more than that evaluated from the case of cohesive soil. This is possibly due to early soil surface failure in the case of cohesive soil.

\subsection{Evaluation of improved $p$-y curves}

Prediction of p-y curve in the applied load direction for the effect of axial load capacities on the lateral pile response is 
illustrated in Figure 7. This figure shows the effect of pile slenderness ratio L/D and soil type for different axial loads. The curves represent the new observation of this kind of loading which is never been observed before. All previous researches include only the effect of pure lateral load on the lateral pile response. This study tends to increase the understanding regarding the lateral pile response in actual case of loading (i.e. axial as well as lateral loads).

In this investigation, larger effect of the load combination in case of cohesionless soil can also be observed and significantly less for cohesive soil. This is possibly due to the increased in lateral pile capacity when both axial and lateral load are carried at the same time. This assessment has made improvement on the predicted p-y design curve which was proposed previously only for the case of pure lateral load. The results can increase the understanding regarding the lateral pile response under load combination. At the end, the improved p-y curve will be used to derive p-multiplier for the design of piles within group.

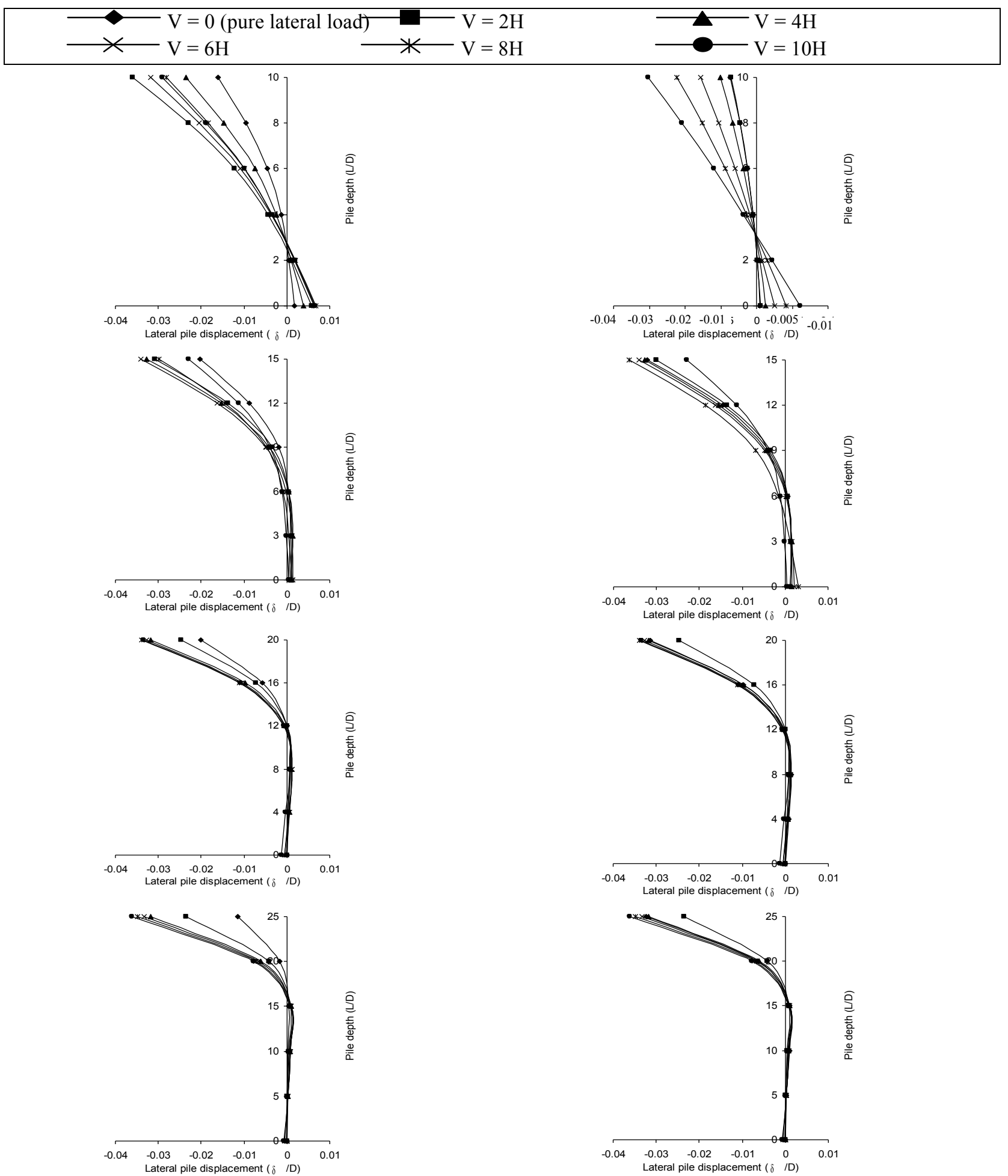

(a)

(b)

Fig. 4. Influence of vertical load intensities, V, on the lateral pile displacement (a) cohesionless soil and (b) cohesive soil 


\begin{tabular}{|c|c|c|c|c|}
\hline$\rightarrow \mathrm{V}=2 \mathrm{H}$ & $\triangle \mathrm{V}=4 \mathrm{H}$ & $\mp V=6 \mathrm{H}$ & $*-\mathrm{V}=8 \mathrm{H}$ & $* \mathrm{~V}=10 \mathrm{H}$ \\
\hline
\end{tabular}
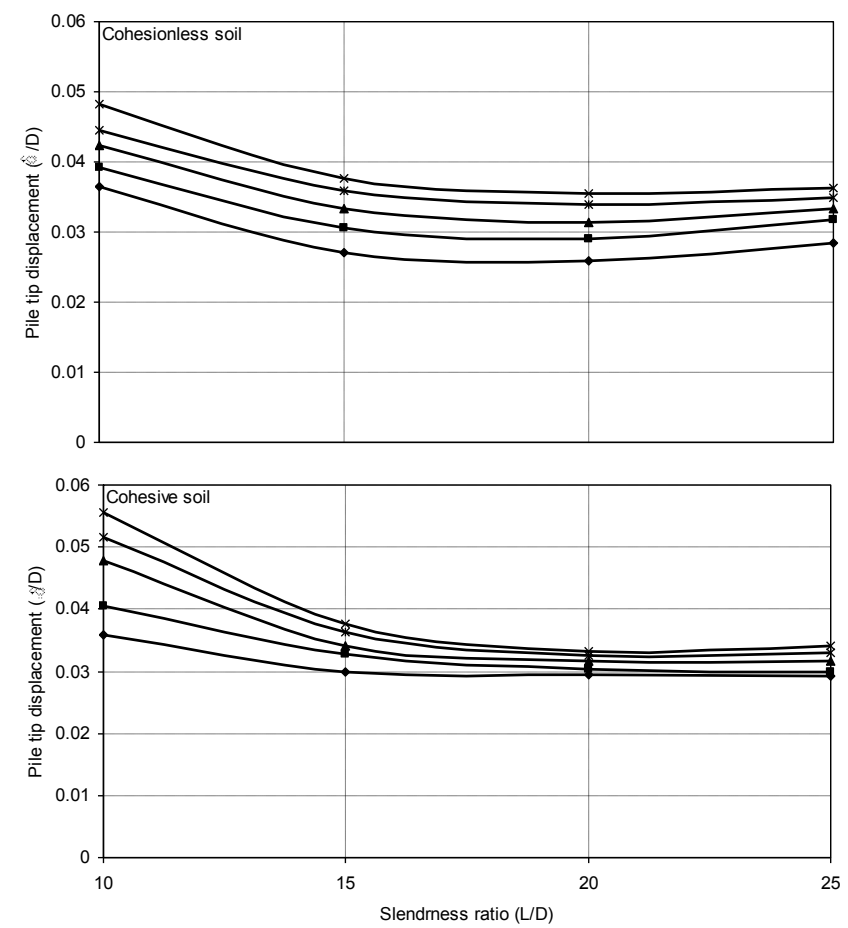

Fig. 5 Predicted lateral tip displacement vs. pile slenderness ratio of pile carried different combination of loads.

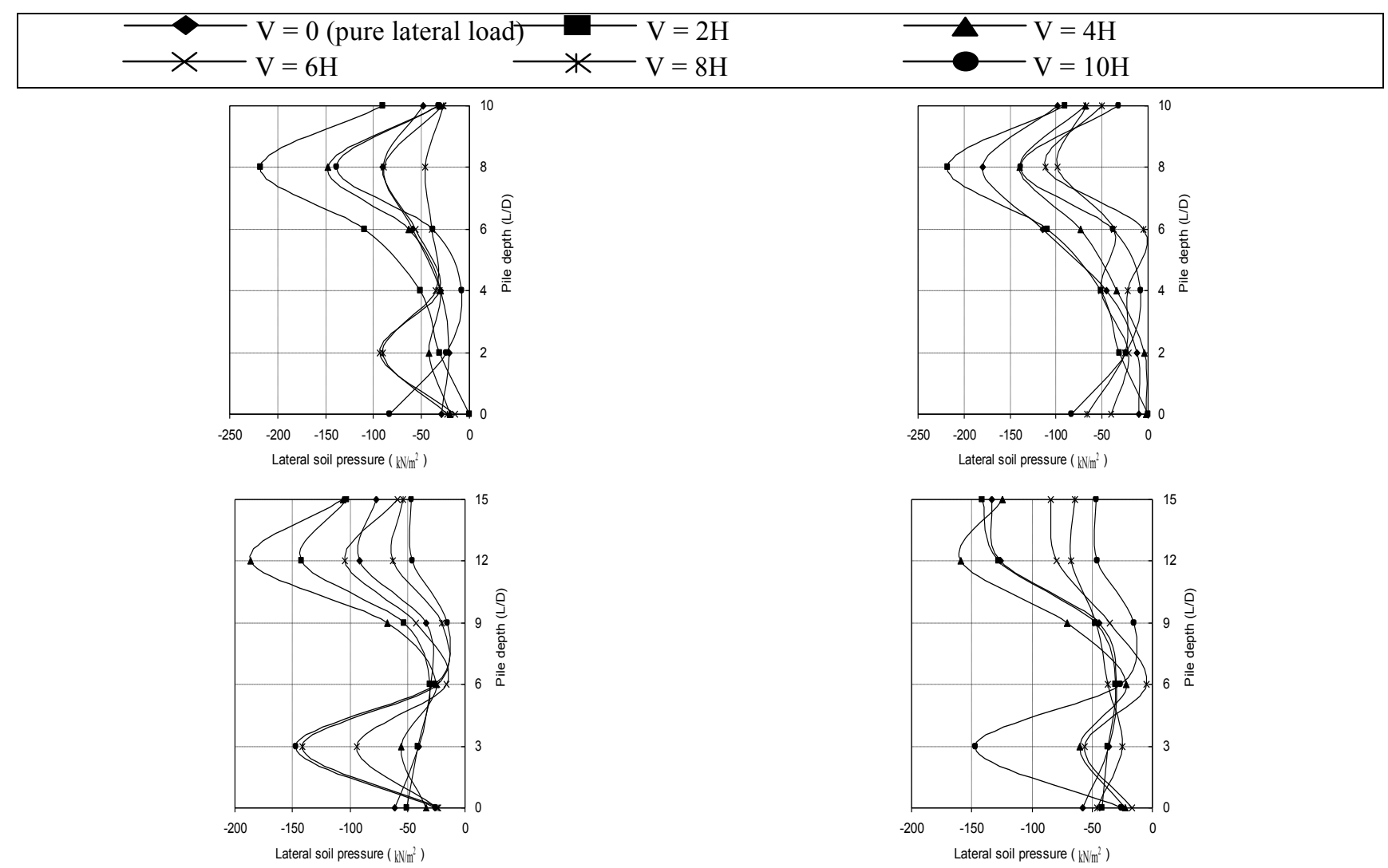



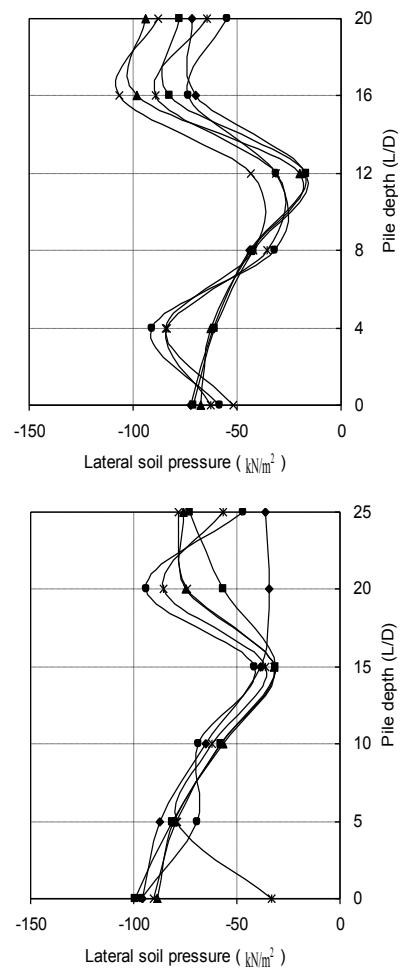

(c)
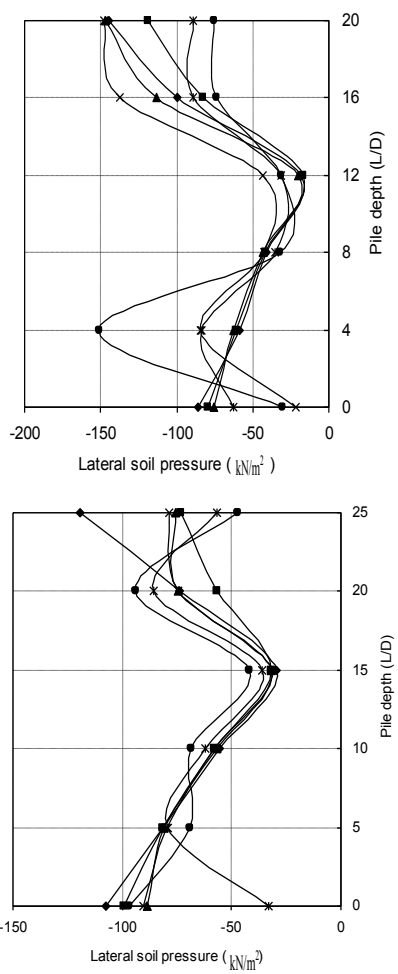

(d)

Fig. 6. Influence of vertical load intensities, V, on the lateral soil pressure, (a) cohesionless soil and (b) cohesive soil
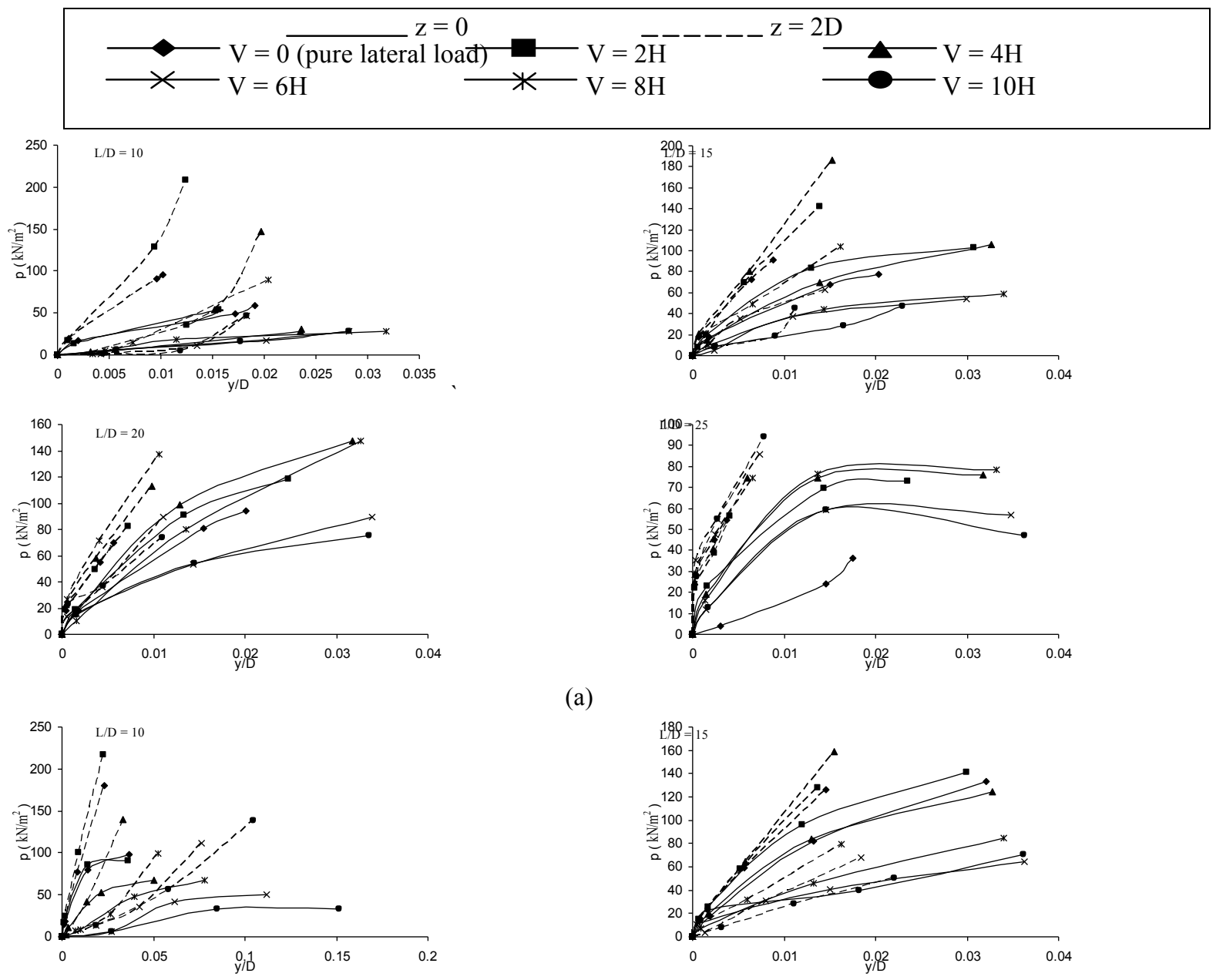

(a)

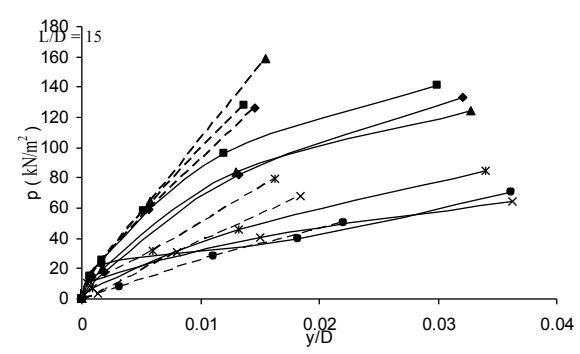




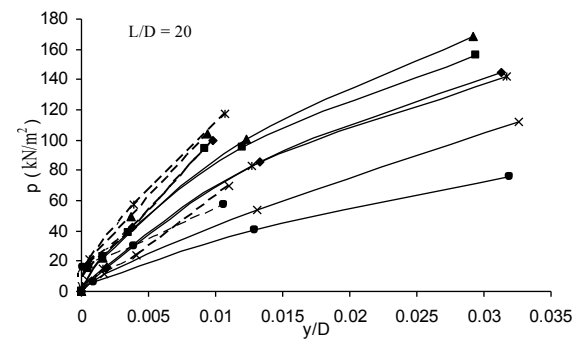

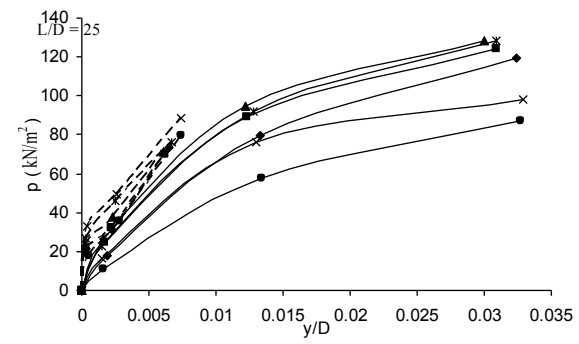

(b)

\section{Conclusions}

The lateral pile deformation and lateral soil resistance are always influenced by the combination of loads as well as pile slenderness ratio $(\mathrm{L} / \mathrm{B})$. For the pile of $(\mathrm{L} / \mathrm{D}=10)$, the point of inflection is $2-2.5 \mathrm{D}$ from the base of the pile, while the pile of $(\mathrm{L} / \mathrm{D}=15)$ the point position is $6 \mathrm{D}$ from the base. On the other hand, for the long pile $(\mathrm{L} / \mathrm{D}=20)$ and $(\mathrm{L} / \mathrm{D}=$ 25 ), the point of inflection (fracture point) is $12 \mathrm{D}$ and $15 \mathrm{D}$ from the base, respectively.

The lateral deflection is increased with the increase of the axial load in case of cohesionless soils. While, in case of cohesive soil, reduces in lateral pile displacement occurred when applied low axial load (i.e. V less than $4 \mathrm{H}$ ) and is increased when axial load level (i.e. V more than $6 \mathrm{H}$ ) has been increased.

The axial load is made a redistributes of the lateral soil pressures and made a change on the corresponding $p-y$ curve. The values of maximum lateral soil pressure are occurred at $\mathrm{L} / 5 \mathrm{D}$ from the ground surface (pile tip). The surface resistance has reached the minimum value but did not reach zero under all vertical loads for both cases of cohesionless and cohesive soils. Finally, the combination of axial and lateral load is largely affected on the predicted p-y design curves.

This is an Open Access article distributed under the terms of the Creative Commons Attribution License

\section{References}

1. S. Karthigeyan, , V. V. G. S. T., Ramakrishna, and K. Rajagopal. "Influence of vertical load on the lateral response of piles in sand." Computer and Geotechnics, (2006), Vol. 33, pp.121-131.

2. S. Karthigeyan, , V. V. G. S. T., Ramakrishna, and K. Rajagopal. "Numerical Investigation of the Effect of Vertical Load on the Lateral Response of Piles." Journal of Geotechnical and Geoenvironmental Engineering, (2007). Vol. 133, No. 5, pp. 512-521.

3. H. G. Poulos, and E. H. Davis. "Pile Foundation Analysis and Design" . (1980) John Wiley \& Sons, New York

4. N. R. Patra, and P. J. Pise,. "Ultimate Lateral Resistance of Pile Groups in Sand". Journal of Geotechnical and Geoenvironmental Engineering, (2001)Vol. 127, No. 6, pp. 481-487.

5. A. Muqtadir, and C. S. Desai, "Three-dimensional analysis of a pile-group foundation." International Journal of Numerical and Analytical Methods Geomechanics, (1986). Vol. 10, pp. 41-58.

6. A. M. Trochanis, , J. Bielak, and P. Christiano, "Threedimensional nonlinear study of piles." Journal of Geotechnical Engineering, ASCE, (1991). Vol. 117, No. 3, pp. 429.447.

7. B.-T. Kim, and Y.-S. Kim, "Back analysis for prediction and behavior of laterally loaded single piles in sand." KSCE Journal of Civil Engineering, ( 1999). Vol. 3, No.3, pp. 273-288.

8. Z. Yang, and B. Jeremiæ, "Study of soil layering effects on lateral Loading behavior of piles." J. Geotech. Geoenvir. Eng. ASCE, (2005). Vol. 131, No. 6, pp. 762770 .
9. J. M., Abbas, Z. Chik and M. R. Taha. "Influence of group configuration on the lateral pile group response subjected to lateral load". Electronic Journal of Geotechnical Engineering (2010) Vol. 15, pp.761-772.

10. J. M. Abbas "Evaluation conduct of deep foundations using 3D finite element approach". American Journal of Civil Engineering (2013) Vol. 1, No. 3, pp.129-134.

11. R.B.J. Brinkgreve, and W. Broere, . PLAXIS 3D FOUNDATION - version 1. (2004) Netherlands.

12. D. M. Potts, and L. Zdravkovic, "Finite element analysis in geotechnical engineering: theory". (1999). Thomas Telford. Heron Quay, London.

13. K. Johnson, P. Lemcke, , W. Karunasena, and N. Sivakugan, "Modelling the load - deformation response of deep foundation under oblique load." Environment Modelling and Software, (2006). Vol. 21, pp. 1375-1380. A. Jamaludin, and A. N. Hussein, "The performance of large diameter bored piles used for road project in Malaysia." Proceedings of the $3^{\text {rd }}$ International Geotechnical Seminar on Deep Foundation on Bored and Auger Piles, Ghent, Belgium, (1998). pp. 335-338.

14. N. F. Ismael, "Lateral loading tests on bored piles in cemented sands." Proceedings of the $3^{\text {rd }}$ International Geotechnical Seminar on Deep Foundation on Bored and Auger Piles, Ghent, Belgium (1998). pp.137-144.

15. B. B. Broms "Lateral resistance of Piles in Cohesive Soils." Journal of the Soil Mechanics and Foundations Division, ASCE, (1964a). Vol. 90, No. 2, pp. 27-63.

16. B. B. Broms "Lateral resistance of Piles in Cohesionless Soils". Journal of the Soil Mechanics and Foundations Division, ASCE, (1964b). Vol. 90, No. 3, pp. 123-156. 